\title{
Bardet-Biedl syndrome: a molecular and phenotypic study of 18 families
}

\author{
P L Beales, A M Warner, G A Hitman, R Thakker, F A Flinter
}

\begin{abstract}
The autosomal recessive disorder BardetBiedl syndrome is characterised by retinal degeneration, polydactyly, obesity, mental retardation, hypogenitalism, renal dysplasia, and short stature. It is heterogeneous with at least four gene loci (BBS1-4) having been mapped to date. We have studied 18 multiply affected families noting the presence of both major and minor manifestations. Using a fluorescently based PCR technique, we genotyped each family member and assigned linkage to one of the four loci. Given this degree of heterogeneity we hoped to find phenotypic differences between linkage categories.

We found $44 \%$ of families linked to 11 q13 (BBS1) and 17\% linked to 16q21 (BBS2). Only one family was linked to $15 q 22$ (BBS4) and none to $3 p 12$. We conclude that BBS1 is the major locus among white Bardet-Biedl patients and that BBS3 is extremely rare. Only subtle phenotypic differences were observed, the most striking of which was a finding of taller affected offspring compared with their parents in the BBS1 category. Affected subjects in the BBS2 and 4 groups were significantly shorter than their parents. Twenty eight percent of pedigrees did not show linkage to any known locus, evidence for at least a fifth gene. We conclude that the different genes responsible for Bardet-Biedl syndrome may influence growth characteristics such as height.

(F Med Genet 1997;34:92-98)
\end{abstract}

Division of Medical and Molecular Genetics, UMDS, Guy's Hospital, London SE1 9RT, UK P L Beales

A M Warner

F A Flinter

Medical Unit, Royal London Hospital, Whitechapel, London, UK

G A Hitman

MRC Molecular Endocrinology Unit, RPMS, Hammersmith Hospital, London, UK R Thakker

Correspondence to: Dr Beales.

Received 22 May 1996 Revised version accepted fo publication 3 October 1996 ing ability are among the commonest causes of renal impairment. Minor features include hepatic fibrosis, diabetes mellitus, reproductive abnormalities, endocrinological disturbances, Renal failure is the major cause of morbidity Chronic glomerulonephritis, characteristic short stature, hearing loss, developmental delay, and speech deficit. BBS is distinct from the much rarer Laurence-Moon syndrome in which retinal pigmentary degeneration, mental retardation, and hypogenitalism occur with a progressive spastic paraparesis and distal muscle weakness but without polydactyly. ${ }^{4}$

The frequency of BBS varies with the highest prevalence of 1 in 13500 occurring in the Middle East. ${ }^{5}$ It is far less common in Europe with a rate of 1 in 160000 found in Switzerland ${ }^{6}$ and 1 in 125000 in the United Kingdom (P L Beales unpublished data).

Recently, genetic heterogeneity has been confirmed with the finding of four gene loci on chromosomes 11 (BBS1), 16 (BBS2), 3 (BBS3), and 15 (BBS4) respectively, each associated with a similar phenotype..$^{7-10}$ The chromosome 11 locus study used 32 nuclear families mainly from North America and the remaining loci were mapped using three large consanguineous Bedouin families.

We were interested to establish the proportion of our nuclear families mapping to each of these loci and whether there were any particular phenotypic differences associated with the different loci.

\section{Materials and methods}

\section{FAMILIES}

Eighteen families of mixed ethnic origin were enrolled in this study (fig 1). Fourteen were of north European descent (one of which is of Ashkenazi origin) and four were of Middle Eastern origin. Each family comprised a minimum of two affected members with a maximum of four affected sibs. In four out of the 18 $(22 \%)$ pedigrees, the parents were related. There were 41 affected patients with BBS and 28 available for examination.

All patients have been examined by a geneticist (PLB) and each fulfilled at least four out of five cardinal features. A thorough personal and family history was obtained by means of a standardised questionnaire. Each patient had a diagnosis of retinal degeneration confirmed by an ophthalmologist. The height and weight of each family member was measured. The results of radiological and ultrasound investigations were sought from the relevant hospitals.

LINKAGE ANALYSIS

DNA was extracted from leucocytes and each family member was genotyped using the polymerase chain reaction (PCR) incorporating fluorescently labelled microsatellite markers flanking known loci. We amplified $40 \mathrm{ng}$ of genomic DNA in $10 \mu \mathrm{l}$ reaction volumes 

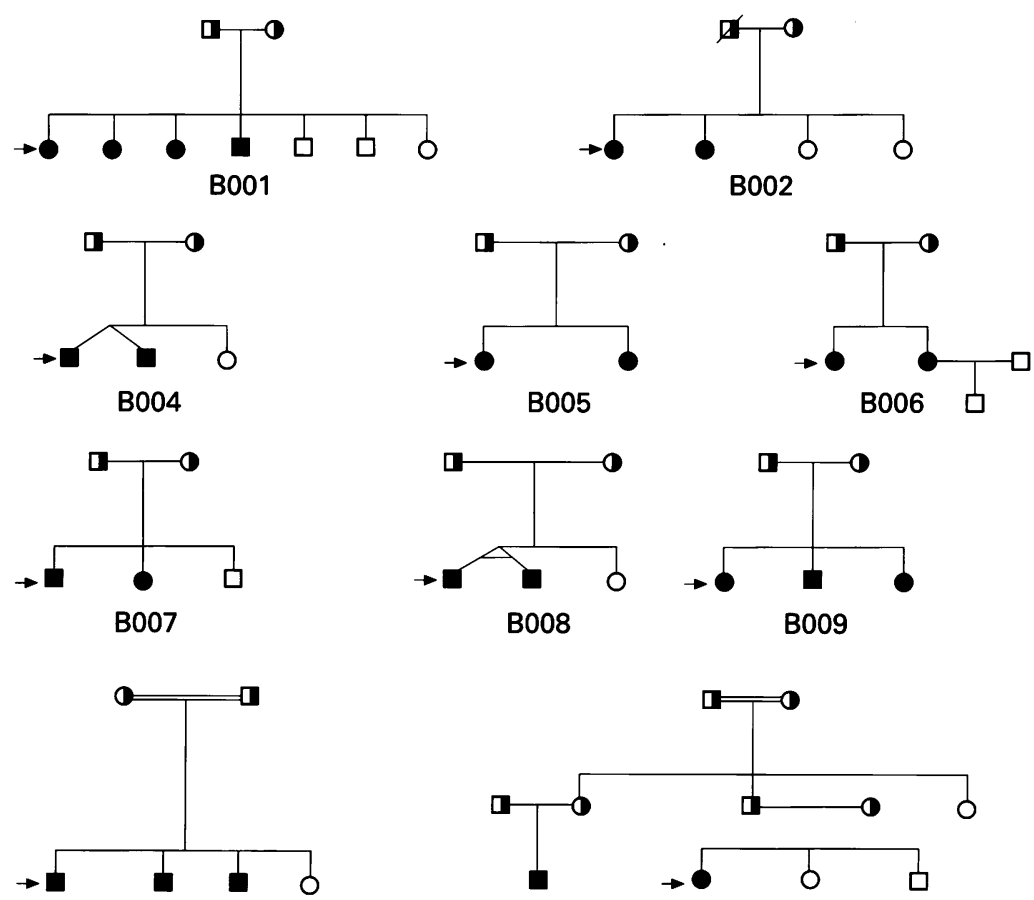

B012
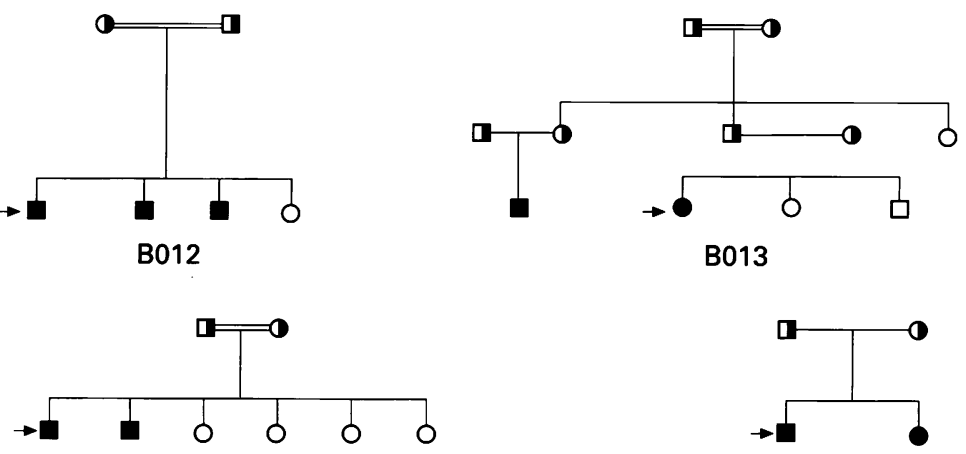

B011

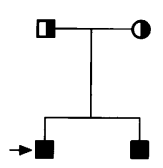

B014

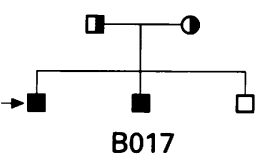

B017

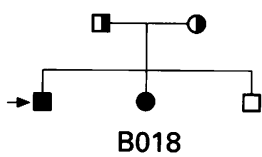

B018

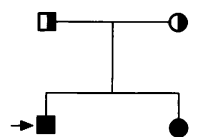

B003

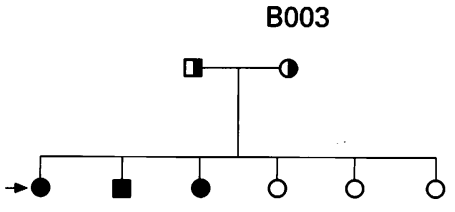

B016
Figure 1 Bardet-Biedl pedigrees studied.

containing $1 \mu \mathrm{l}$ PCR buffer $(10 \times)(670 \mathrm{mmol} / 1$ Tris-HCl, pH 8.0, $166 \mathrm{mmol} / 1 \mathrm{NH}_{4} \mathrm{SO}_{4}, 67$ $\left.\mathrm{mmol} / 1 \mathrm{MgCl}_{2}, 1.7 \mathrm{mg} / \mathrm{ml} \mathrm{BSA}\right), 5 \mathrm{mmol} / 1$ of each dNTP (dATP, dCTP, dGTP, dTTP), 2 pmol of each fluorescent primer, and 0.6 units $\mathrm{Taq}$ polymerase. Typical reaction conditions were as follows: initial denaturation at $94^{\circ} \mathrm{C}$ for 10 minutes then 24 cycles of $94^{\circ} \mathrm{C}$ for $45 \mathrm{sec}-$ onds, annealing temperatures $54-60^{\circ} \mathrm{C}$ for 45 seconds, extension at $72^{\circ} \mathrm{C}$ for two minutes, and then extension at $72^{\circ} \mathrm{C}$ for 10 minutes.

The PCR products were separated on a $6 \%$ polyacrylamide gel and their fluorescent signal detected by a DNA fragment analyser (ABI 373). Alleles were assigned using the incorporated GENOTYPER software and then tested for two point linkage using MLINK (part of the LINKAGE software package). A model of autosomal recessive inheritance was used.

Three inclusion criteria were used to assign each pedigree to the four known loci. (1) A positive two point lod score. (2) Haplotype analysis was consistent with linkage (fig 2). (3) Negative lod scores and haplotypes in the other three loci.

PHENOTYPE ANALYSIS

Phenotypic parameters were analysed by comparison of affected patients with unaffected heterozygous parents where appropriate. BBS patients were then compared according to the loci to which they were linked.

\section{STATISTICAL ANALYSIS}

To test statistical significance we calculated 95\% confidence intervals (CI) about the means. For a comparison of categorical variables we applied the chi-square test or Fisher's exact test and for continuous variables the Student $t$ test. Statistical significance was supported by values of $\mathrm{p}<0.05$. The body mass index $\left(\mathrm{BMI}=\right.$ weight $\left.(\mathrm{kg}) / \mathrm{height}^{2}(\mathrm{~m})\right)$ was calculated for each family member.

\section{Results}

EYE DISEASE

The mean age at diagnosis of BBS was 14.9 years. Almost all subjects (96\%) had evidence of retinal degeneration either on ophthalmoscopy or by electroretinography (ERG) and visually evoked responses (VER) (table 1). The one patient without eye disease was 6 years old and may yet develop eye changes. There was a significant difference in mean age at onset of night blindness between locus categories (BBS1 < BBS4: $\mathrm{p}=0.003, \mathrm{BBS} 2<\mathrm{BBS} 4$ : $\mathrm{p}=0.02)$. There was also a significant difference within the BBS1 category between males and females $(p<0.05)$ but this finding was not observed elsewhere. There was no intracategory sex difference seen at age of national registration of blindness. There was no significant intercategory difference seen for the mean time interval between onset of visual loss (night blindness) and complete blindness.

\section{POLYDACTYLY}

Seventy two percent of patients had a well differentiated postaxial extra digit in at least one limb and four (22\%) just had skin tags. In all but one case the extra digits involved the lateral aspect of the hand or foot; in the remaining case the extra digit was placed between the fourth and fifth toe. There was no significant difference in the distribution of extra digits between the hands or feet nor in laterality between limbs. The small proportion of syndactyly seen was confined to the 2 nd and 3rd toes in the feet.

HEIGHT AND BODY MASS INDEX

Previous descriptions of this syndrome reported a significant decrease in the height of adult patients compared with their unaffected parents; however, we did not see any significant mean difference ( $1.66 \mathrm{~m}$ in offspring versus $1.69 \mathrm{~m}$ in parents) until families were separated by locus assignment (table 2 ). Within the BBS1 category, affected sons were significantly taller than their fathers (mean $6 \mathrm{~cm}, \mathrm{p}=0.04$ ). A more striking result is seen when affected daughters are compared with their mothers 

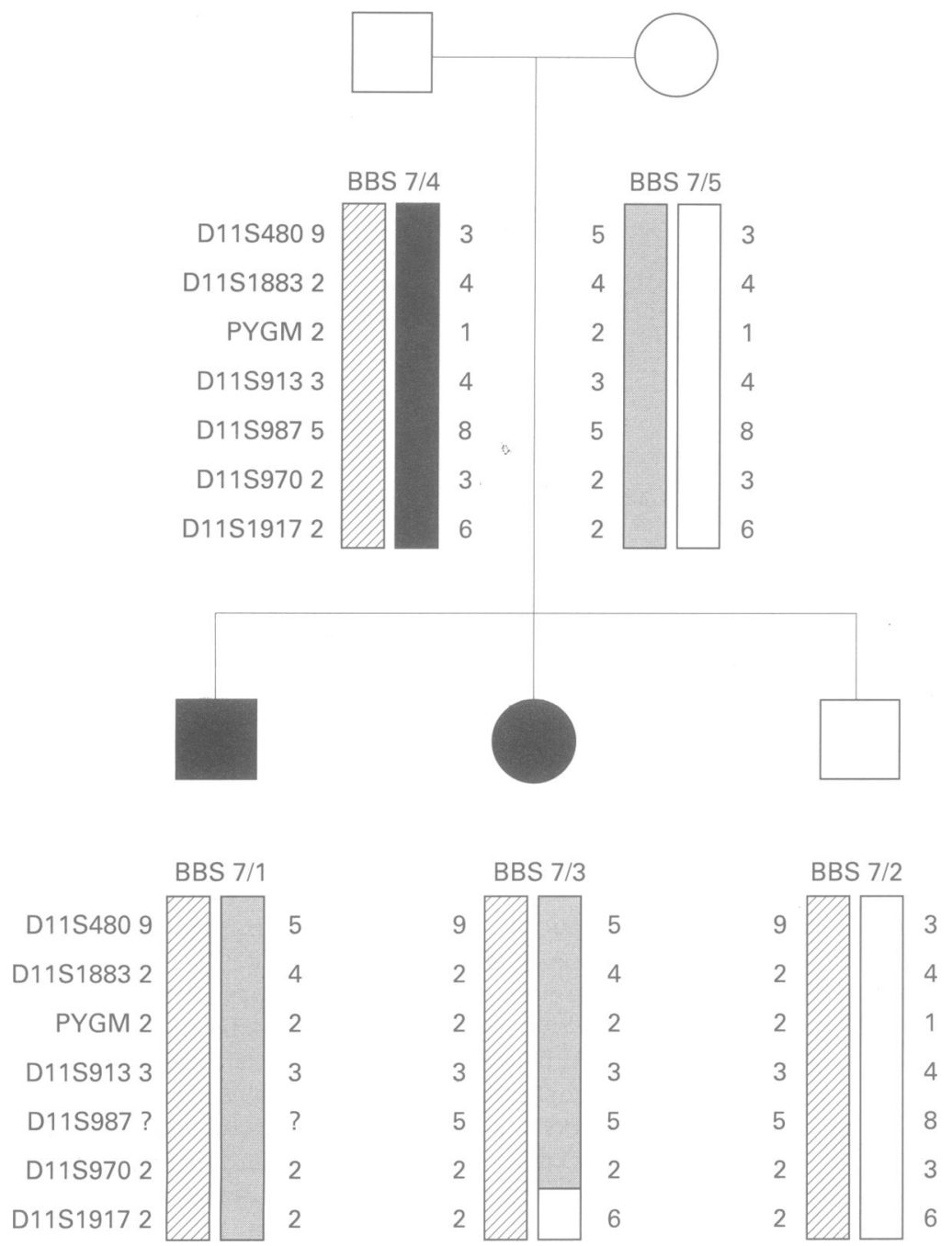

Figure 2 Family 7 showing haplotypes in the 11 q13 interval.

Table 1 Visual loss

\begin{tabular}{|c|c|c|}
\hline Proportion with retinitis pigmentosa & $\begin{array}{l}24 / 25 \\
(96 \%)\end{array}$ & p value \\
\hline $\begin{array}{l}\text { Mean age of onset night blindness } \\
\text { Chromosome } 11\end{array}$ & $9 y$ & \\
\hline Mean age males $(n=7)$ & $6 y$ & \\
\hline Mean age females $(n=6)$ & $11.3 \mathrm{y}$ & $p=0.049$ \\
\hline \multicolumn{3}{|l|}{ Chromosome 16} \\
\hline Mean age males $(n=3)$ & $3.6 \mathrm{y}$ & \\
\hline Mean age females $(n=5)$ & $4.4 \mathrm{y}$ & $\mathrm{p}=0.2$ \\
\hline \multicolumn{3}{|l|}{ Chromosome 15} \\
\hline Mean age females $(n=2)$ & $32 \mathrm{y}$ & \\
\hline \multicolumn{3}{|l|}{ Chromosome 11} \\
\hline Mean age males $(n=4)$ & $12.2 \mathrm{y}$ & \\
\hline Mean age females $(n=3)$ & $15.3 \mathrm{y}$ & $\mathrm{p}=0.3$ \\
\hline \multicolumn{3}{|l|}{ Chromosome 16} \\
\hline Mean age males $(n=3)$ & $13.3 \mathrm{y}$ & \\
\hline Mean age females $(n=2)$ & $11.5 \mathrm{y}$ & $p=0.3$ \\
\hline \multicolumn{3}{|l|}{ Chromosome 15} \\
\hline Mean age females $(n=1)$ & $43 y$ & \\
\hline $\begin{array}{l}\text { Mean time interval from onset to } \\
\text { complete loss of vision }\end{array}$ & $7.2 \mathrm{y}$ & \\
\hline
\end{tabular}

(daughters: mean $11 \mathrm{~cm}$ taller, $\mathrm{p}=0.02$ ). In the BBS2 category, the daughters were significantly shorter than their mothers, but the sons were identical in mean height to their fathers. Although there are only two females in the BBS4 category, they represent the furthest extremes in mean height $(1.32 \mathrm{~m} v 1.67 \mathrm{~m}$ in mother, a difference of $35 \mathrm{~cm}$ ).

As predicted, the mean weight was significantly increased in adult offspring $(p=0.001)$. Again, when analysed by locus and sex there was a significant increase over parents except in BBS2 sons who did not reach significance. A better index of body mass (BMI, $\mathrm{kg} / \mathrm{m}^{2}$ ) incorporates height and weight and overall was highly significant when offspring were compared with their parents $(p=0.0001)$. Surprisingly, sons in all categories did not differ significantly from their fathers in this respect, although daughters did (BBS1: $p=0.01, \mathrm{BBS} 2$ : $\mathrm{p}=0.03$ ). The BMI difference was greatest in the BBS4 pedigree (daughters: 44.8 , mother: 26.2).

RENAL AND GENITOURINARY ANOMALIES

All males had small external genitalia. Undescended or maldescended testes were present at birth in a quarter of males. Details of female genital anomalies are not available. Pubertal delay was reported in less than $10 \%$. Urinary tract infections and anomalous structure (where ultrasound or intravenous pyelography had been performed) were present in about $10 \%$ and $20 \%$, respectively. Both of these were confined to BBS1. Chronic renal failure was observed in all categories, with a loss of renal function of $20-80 \%$. Polydipsia with polyuria were found to be present in a third of al patients. Each of these patients had either a random urinary or blood glucose measurement and only three had formal glucose tolerance tests; none of them was diagnosed with overt diabetes mellitus.

Overall, the mean birth weight did not differ from the national average, but within the subgroups patients in BBS2 were significantly lighter.

\section{DEVELOPMENT}

Developmental delay, primarily in gross and fine motor skills, was reported in over a third of patients (table 3 ). The delay in walking and talking was, on average, one year. A notable and persistent feature reported by relatives was dyspraxia and general clumsiness $(>50 \%)$.

Hearing deficit in childhood was reported in $35 \%$ (UK prevalence $\sim 20 \%$ ), and in nearly al cases comprised a conductive loss associated with chronic middle ear effusion. All of these had required insertion of grommets as therapy but had resolved by adulthood. Speech deficit has been reported infrequently in published reports but was present in over $60 \%$ of patients in this study. Most cases involved poor articulation of speech with slurring of words and dropping of consonants, all of which improved with speech therapy.

\section{LEARNING DISABILITIES}

Although the need for special educational help was common in this group of patients there was no statistical difference between locus categories. However, there was a subjective difference noted in terms of the level of help required. Twenty eight percent of children were able to remain in mainstream education although with classroom aids, while another $28 \%$ went into special establishments based on educational needs (apart from visual loss). Of this latter group most were in the BBS2 and BBS4 category. The two women in the BBS4 group 
Table 2 Comparisons of height, weight, and body mass index between patients and their parents by locus category

\begin{tabular}{|c|c|c|c|c|c|c|c|c|c|}
\hline & Mean height $(m)(C I)$ & $\begin{array}{l}\text { No } \\
\text { studied }\end{array}$ & $p$ value & Mean weight $(\mathrm{kg})(\mathrm{CI})$ & $\begin{array}{l}\text { No } \\
\text { studied }\end{array}$ & $p$ value & Mean BMI $\left(\mathrm{kg} / \mathrm{m}^{2}\right)(C I)$ & $\begin{array}{l}\text { No } \\
\text { studied }\end{array}$ & $p$ value \\
\hline \multicolumn{10}{|c|}{ Overall } \\
\hline \multicolumn{10}{|c|}{ Offspring $\mathrm{v}$ parents } \\
\hline Offspring & $1.66(1.58$ to 1.74$)$ & 17 & & $103.1(88.6$ to 117.6$)$ & 14 & & $38.1(33.4$ to 42.8$)$ & 14 & \\
\hline Parents & $1.69(1.64$ to 1.74$)$ & 17 & 0.27 & $74.6(67.5$ to 81.8$)$ & 15 & 0.001 & $26.1(23.7$ to 33.1$)$ & 15 & 0.0001 \\
\hline \multicolumn{10}{|l|}{ BBS1 } \\
\hline \multicolumn{10}{|l|}{ Sons $\mathrm{v}$ fathers } \\
\hline Sons & $1.8 \quad(1.77$ to 1.83$)$ & 4 & & 96.5 (84.9 to 108.1$)$ & 3 & & $29.2(25.7$ to 32.7$)$ & 3 & \\
\hline Fathers & $1.74(1.7$ to 1.78$)$ & 6 & 0.04 & $78.7(68.5$ to 88.9$)$ & 5 & 0.04 & $26.0(23.2$ to 28.8$)$ & 5 & 0.11 \\
\hline \multicolumn{10}{|c|}{ Daughters v mothers } \\
\hline Daughters & $1.71(1.63$ to 1.79$)$ & 6 & & $121.4(88.3$ to 154.5$)$ & 5 & & 40.6 (33.6 to 47.6$)$ & 5 & \\
\hline Mothers & $1.60(1.56$ to 1.64$)$ & 5 & 0.02 & $71.7(56.2$ to 87.2$)$ & 4 & 0.02 & $28.2(22.2$ to 34.2$)$ & 4 & 0.01 \\
\hline \multicolumn{10}{|l|}{ BBS2 } \\
\hline \multicolumn{10}{|l|}{ Sons $\mathrm{v}$ fathers } \\
\hline Sons & $1.76(1.59$ to 1.93$)$ & 2 & & 90.7 (62.7 to 118.7$)$ & 2 & & $29.0(23.5$ to 29.7$)$ & 2 & \\
\hline Fathers & $1.76(1.65$ to 1.87$)$ & 3 & 0.49 & 82.7 (63.7 to 101.7$)$ & 3 & 0.34 & $26.6(23.5$ to 29.7$)$ & 3 & 0.19 \\
\hline \multicolumn{10}{|c|}{ Daughters v mothers } \\
\hline Daughters & $1.48(1.46$ to 1.5$)$ & 6 & & $105.0(86.4$ to 123.6$)$ & 2 & & $47.9(40.7$ to 55.2$)$ & 2 & \\
\hline Mothers & $1.60(1.56$ to 1.64$)$ & 5 & 0.04 & $71.0(65.5$ to 76.5$)$ & 3 & 0.07 & 27.5 (23.0 to 32.0$)$ & 3 & 0.03 \\
\hline
\end{tabular}

have severe learning difficulties. Both are unable to read, write, or handle money and are wholly dependent on the full time care of their mother.

\section{ASTHMA}

Atopic asthma (which necessitated regular use of beta agonists) was present in $24 \%$ of patients and was confined to the BBS1 category (table $3)$.

\section{LOCUS ASSIGNMENT}

We tested eight markers from 11q13 (BBS1) and found the highest lod scores in the interval D11S480-(0.019)-D11S1883-(0.001)-PYGM(0.003)-D1 1S913 (linear order with recombination frequencies) (fig 3). Forty four percent of pedigrees gave positive lod scores and consistent haplotypes (table 4). No recombinants were observed in this interval. From 16q21 (BBS2) we tested D16S408-(0.064)-D16S3089-(0.01)D16S514-(0.018)-D16S265; 17\% of pedigrees mapped to this interval with no recombinants observed. From 15q22 (BBS4) the linear order of markers is D15S204-(0.005)-D15S1026(0.011)-D15S114-(0.011)-D15S984. A single family mapped to this locus constituting $6 \%$ of pedigrees. No family mapped to chromosome 3p12 (BBS3). One family was not sufficiently informative to assign linkage but five families (28\%) gave negative lod scores and failed on haplotype analysis to map to any of the four BBS loci. Four of these families are consan- guineous and of Middle Eastern/Asian origin (Iraq (Kurdish), Iran, Turkey (Kurdish), India).

\section{Discussion}

Genetic non-allelic heterogeneity has been well described in many monogenic diseases (for example, retinitis pigmentosa). ${ }^{11}$ The four separate BBS loci appear to result in similar phenotypes with a single report suggesting subtle differences in three families. ${ }^{12}$ We have presented data on nuclear families from various ethnic backgrounds in which the $11 \mathrm{q} 13$ locus accounts for the majority of cases (almost half). The $16 \mathrm{q} 21$ locus is the second most common with the $15 \mathrm{q} 22$ and $3 \mathrm{p} 12$ loci apparently very rare. The lack of established linkage in four consanguineous families from the Middle East and Asia suggests the presence of at least a fifth BBS locus, and it would seem that locus distribution is subject to regional variation.

Interlocus phenotype comparisons have not previously been reported for all four loci, and although our study population is small we made a number of observations which will require verification in larger studies. The late mean age at diagnosis of 15 years is confirmed in a wider population pilot study (P L Beales, unpublished data) and probably represents a combination of medical unawareness and the variable phenotypic expression. Although there was a statistically significant difference in mean age at onset of retinal degeneration between loci, these results must be interpreted with caution given that the BBS4 group is represented by

Table 3 Developmental abnormalities (mean \% by locus)

\begin{tabular}{|c|c|c|c|c|}
\hline & Overall & $B B S 1$ & $B B S 2$ & $B B S 4$ \\
\hline Birth weight $(\mathrm{g})$ & 3230 & $\begin{array}{l}3480 \\
\mathrm{BBS} 1 \text { v } 2 \mathrm{p}=0.05\end{array}$ & $\begin{array}{l}2940 \\
\mathrm{BBS} 2 \text { v } 4 \mathrm{p}=0.14\end{array}$ & $\begin{array}{l}2780 \\
\mathrm{BBS} 4 v 1 \mathrm{p}=0.38\end{array}$ \\
\hline Developmental delay (\%) & 36 & $\begin{array}{l}12.5 \\
\mathrm{BBS} 1\end{array}$ & $\begin{array}{l}55.5 \\
\mathrm{BBS} 2 \text { v } 4 \mathrm{p}=0.23\end{array}$ & $\begin{array}{l}100 \\
\mathrm{BBS} 4 v 1 \mathrm{p}=0.005\end{array}$ \\
\hline Dyspraxia/poor coordination & 53.8 & $\begin{array}{l}56.2 \\
\mathrm{BBS} 1\end{array}$ & $\begin{array}{l}33.3 \\
\mathrm{BBS} 2\end{array}$ & $\begin{array}{l}100 \\
\mathrm{BBS} 4 v 1 \mathrm{p}=0.23\end{array}$ \\
\hline Hearing deficit (conductive loss) (\%) & 34.6 & $\begin{array}{l}31.2 \\
\mathrm{BBS} 1 \vee 2 \mathrm{p}=0.5\end{array}$ & $\begin{array}{l}44.4 \\
\mathrm{BBS} 2 \text { v } 4 \mathrm{p}=0.23\end{array}$ & $\begin{array}{l}0 \\
\text { BBS4 } v 1 \mathrm{p}=0.35\end{array}$ \\
\hline Speech deficit requiring therapy (\%) & 61.5 & $\begin{array}{l}50 \\
\mathrm{BBS} 1 v 2 \mathrm{p}=0.42\end{array}$ & $\begin{array}{l}66.7 \\
\mathrm{BBS} 2 \vee 4 \mathrm{p}=0.34\end{array}$ & $\begin{array}{l}100 \\
\mathrm{BBS} 4 v 1 \mathrm{p}=0.18\end{array}$ \\
\hline Special educational needs (\%) & 56 & $\begin{array}{l}50 \\
\mathrm{BBS} 1\end{array}$ & $\begin{array}{l}44 \\
\mathrm{BBS} 2\end{array}$ & $\begin{array}{l}100 \\
\mathrm{BBS} 4 v 1 \mathrm{p}=0.18\end{array}$ \\
\hline Asthma (\%) & 24 & $\begin{array}{l}37.5 \\
\mathrm{BBS} 1\end{array}$ & 0 & $\mathrm{BBS} 4 v 1 \mathrm{p}=0.28$ \\
\hline
\end{tabular}


Table 4 Two point maximum lod scores (Zmax) for Bardet-Biedl and one chromosome 11q, 16q, and 15q marker (no linkage to $3 p$ found)

\begin{tabular}{lllll}
\hline Family & Marker & $\theta$ & $Z \max$ & \% linked \\
\hline & 11q13 (BBS1) & & & \\
B003 & D11S1883 & 0.00 & 0.6 & \\
B006 & D11S1883 & 0.00 & 0.6 & \\
B007 & D11S1883 & 0.00 & 0.71 & \\
B008 & D11S1883 & 0.00 & 0.6 & \\
B009 & D11S1883 & 0.00 & 1.2 & \\
B010 & D11S913 & 0.00 & 1.15 & \\
B013 & D11S1883 & 0.00 & 0.81 & \\
B017 & D11S1883 & 0.00 & 0.71 & 44.4 \\
& 16q21 (BBS2) & & & \\
B001 & D16S408 & 0.00 & 1.15 & \\
B004 & D16S408 & 0.00 & 0.43 & \\
B005 & D16S408 & 0.00 & 0.60 & 16.7 \\
& 15q22 (BBS4) & & & \\
B002 & D15S204 & 0.00 & 0.85 & 5.55 \\
B011 & Unlinked (?BBS5) & & & \\
B012 & & & & \\
B014 & & & & \\
B016 & & & & 27.8 \\
B018 & Uninformative at test & & & 5.55 \\
B015 & markers & & & \\
\hline
\end{tabular}

$\star$ Pedigree B010 was informative at D11S1883.

a single family. Nevertheless, within this family the two sisters did not develop any signs of eye disease (night blindness) until both had reached their thirties. The apparent sex differences in eye disease within the BBS1 category are intriguing and may suggest more complex hormonal influences on phenotype. Carmi et $a l^{12}$ observed differences in limb distribution of polydactyly but we did not; however, our BBS4 family did not have any polydactyly for comparison with other loci. Neither did we find any excess of lower limb polydacytyly as previously described. ${ }^{2}$

One of the cited manifesations of BBS is short stature. The finding of excess height in both sons and daughters compared with their parents within the BBS1 category is surprising. In an affluent white population, we would expect predicted heights in offspring to conform to the sex related, midparental height formula. This suggests that the BBS1 locus may be specifically influencing excess height in homozygotes. BBS2 and 4 loci may also have a sex specific influence on height where once again hormones may interact. A similar female specific effect is associated with significantly increased BMI in all categories. Croft et $a l^{13}$ have reported a significantly higher proportion of severely overweight fathers of BBS homozygotes compared with age matched US males. They went on to conclude that a BBS gene may be present in $2.9 \%$ of severely overweight white males. We did not observe any severely or even moderately overweight fathers in our study and, moreover, there was no difference in mean parental height from the national average.

Disorders of puberty were not apparent and all adult patients had normal secondary sexual characteristics and hair distribution. None of the males in this study (or our wider study) has successfully fathered a child; however, two females have given birth to healthy unaffected babies, implying a fundamental difference in gonadal pathogenesis.

The common finding of polydipsia with polyuria was not associated with diabetes mellitus in any cases. This may reflect an underlying nephrogenic concentrating defect which has been described previously.

The birth weights of all except one patient did not differ from the racial average suggesting that BBS is not associated with intrauterine overgrowth. The fact that hyperphagia during childhood was commonly reported by parents $(64.2 \%)$ also suggests that there may be a defect in satiety which only manifests after feeding is established.

The common finding of dyspraxia among BBS patients complicates the problems of visual loss, and can often interfere with daily activities and acquisition of keyboard communication skills. The increased incidence of middle ear infections in BBS children, which usually disappears with age, may point to early abnormalities of middle chamber drainage. Speech deficit does not appear to be a consequence of the conductive hearing loss as it usually presents before this. There is a definite pattern of speech defect, which is often high pitched and nasal with inaccurate word pronunciation. A few cases where videofluorosopy has been performed highlight soft palate hypomobility.

In general, severe learning difficulties are rare, and mild to moderate learning difficulties are usual. We observed a loose association between locus and severity of learning disability, with BBS1 patients requiring

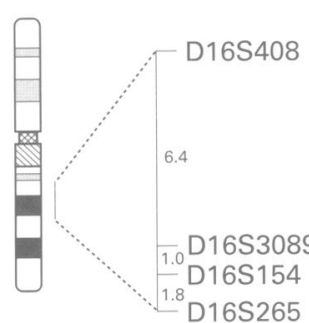

16

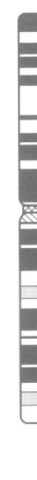

3

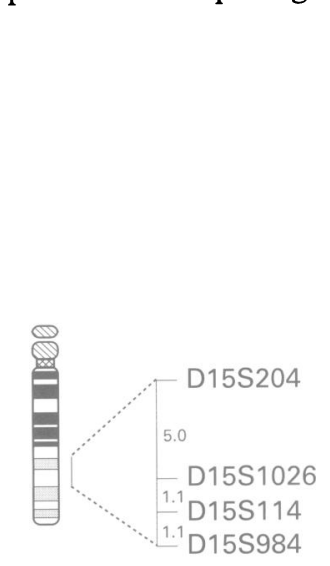

15

Figure 3 Location of microsatellite markers according to locus. 

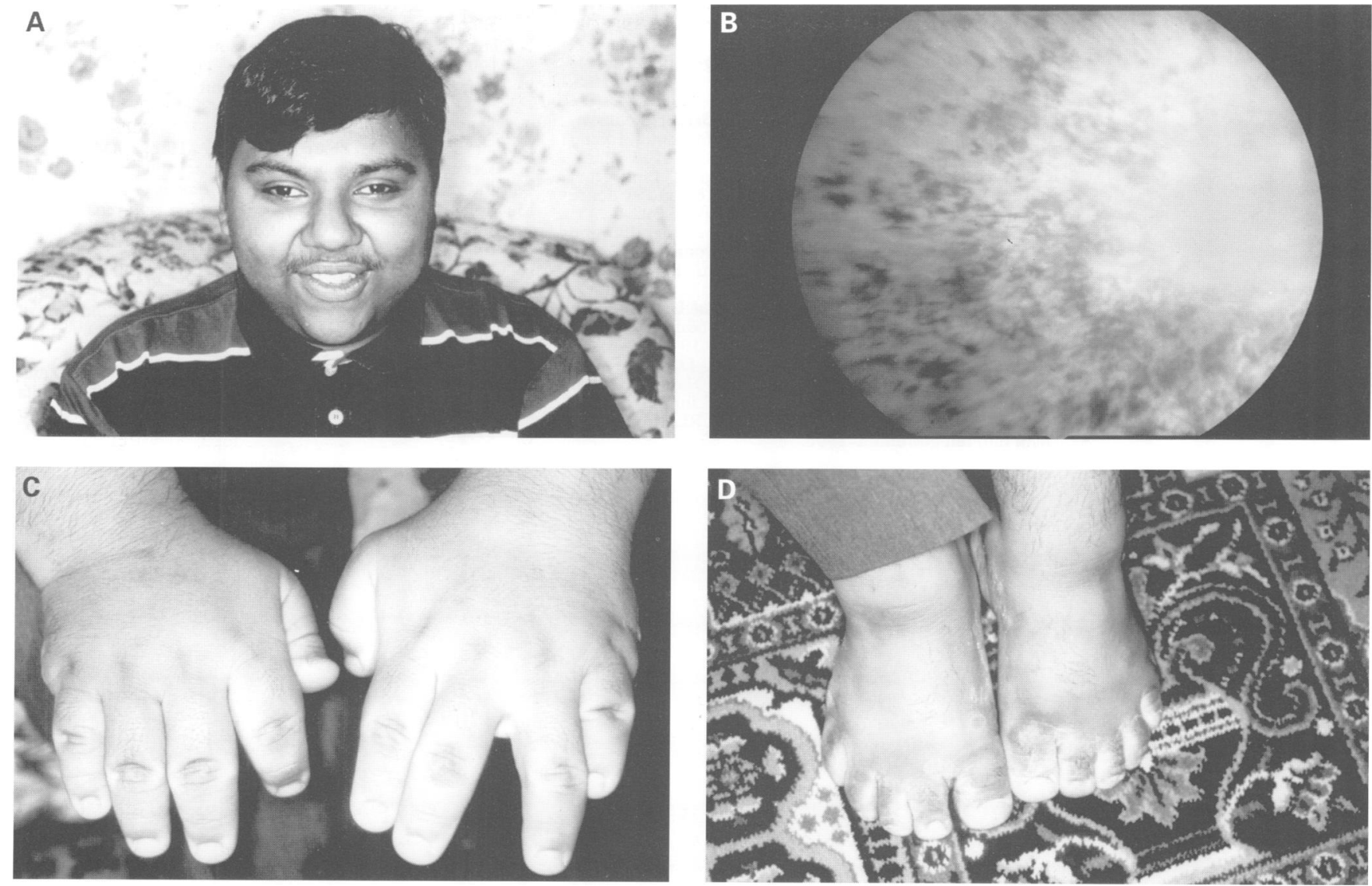

Figure 4 (A) Typical "moon face" appearance of Bardet-Biedl syndrome. (B) Fundoscopic appearance of Bardet-Biedl syndrome showing retinal pigmentation. (C, D) Typical limb abnormalities of Bardet-Biedl syndrome: brachydactyly of both hands and feet with partial syndactyly of the 2nd and 3rd toes.

less help and BBS4 having the most severe difficulties.

Finally, the finding of atopic asthma exclusive to the BBS1 locus is interesting in light of the mapping of a locus for asthma on $11 \mathrm{q} 13 .^{14}$

Croft $e t a l^{15}$ have suggested a possible association of Bardet-Biedl heterozygosity with renal disease, hypertension, and diabetes mellitus as well as obesity. Our observations do not support these findings but such associations can only be confirmed with much larger study numbers.

The diverse range of clinical manifestations in Bardet-Biedl syndrome cannot be explained by known metabolic pathways. The presence of multiple loci suggests a common biochemical pathway in which protein subunits or receptor complexes are at fault. ${ }^{9}$ We conclude that such pathways may influence growth characteristics dependent on the mutation and point at which they are acting. Currently, the most promising strategy to identify BBS genes is to adopt a combined candidate gene and positional cloning approach. ${ }^{16}$ Such efforts may be enhanced by a chance finding of a gross rearrangement. On 11q13, functional candidates such as ROM1 (rod outer segment protein-1) have been excluded ( $\mathrm{R}$ McInnes, personal communication), but other possibilities include FGF and HOX genes thought to be involved in limb formation. ${ }^{17}$ Other clues may come from cross species study of syntenic regions, for example, Drosophila. ${ }^{18}$ The isolation of BBS genes will show hitherto unknown developmental mecha- nisms involved in a diverse range of organs and may shed light on multifactorial diseases such as obesity, hypertension, diabetes, and even asthma.

\section{Conclusions}

Apart from a significant height effect in the BBS1 category (taller affected offspring), we did not observe any outstanding phenotypic feature which might correlate with gene locus. Fig 4 shows some typical dysmorphic features of Bardet-Biedl syndrome. BBS1 is the most commonly represented locus in white families, with no families represented by BBS3. There is strong evidence to suggest the presence of at least one further locus, BBS5.

We thank Drs A Fryer, G Germino, F Hildebrandt, and the International Study of Genetic Renal Diseases for their help in providing pedigrees. We are grateful to $\mathrm{Dr}$ J for their help in providing pedigrees. We are grateful to Dr J Pang and Dr S Forbes for microsatellites and help on $11 \mathrm{q} 13$, and to $\mathrm{Dr} C$ Mathew for advice on linkage. Mr N Smeeton advised on statis-
tics. The study was funded in part by the British Retinitis tics. The study was funded in part by the British Retinitis
Pigmentosa Society. Above all, we thank the families and Pigmentosa Society. Above all, we thank the families and patients who took part in this study.
Medical Research Council Fellowship.

1 Bardet G. Sur un syndrome d'obesite congenitale avec polydactylie et retinite pigmentaire (contribution a l'etude des formes clinique de l'obesite hypophysaire). Thesis, Paris, 1920.

2 Green JS, Parfrey PS, Harnett JD, et al. The cardinal manifestations of Bardet-Biedl syndrome, a form of LaurenceMoon-Biedl syndrome. $N$ Engl $\mathscr{F}$ Med 1989;321:1002-9.

3 Harnett JD, Green JS, Cramer BC, et al. The spectrum of Harnett JD, Green JS, Cramer BC, et al. The spectrum of
renal disease in Laurence-Moon-Biedl syndrome. $N$ Engl $F$
Med 1988;319:615-18.

4 Laurence JZ, Moon RC. Four cases of "retinitis pigmentosa" occurring in the same family, and accompanied by general imperfections of development. Ophthalmol Rev 
5 Farag TI, Teebi AS. Bardet-Biedl and Laurence-Moon syndromes in a mixed Arab population. Clin Genet 1988;33. 78-82.

6 Ammann F. Investigations clinique et génétique sur le syndrome de Bardet-Biedl en Suisse. $\mathcal{f}$ Genet Hum

7 Leppert M, Baird L, Anderson KL, et al. Bardet-Biedl syndrome is linked to DNA markers on chromosome $11 \mathrm{q}$ and is genetically heterogeneous. Nat Genet 1994;7:108-12.

8 Kwitek-Black AE, Carmi R, Duyk GF, et al. Linkage of Bardet-Biedl syndrome to chromosome $16 \mathrm{q}$ and evidence for non-allelic heterogeneity. Nat Genet 1993;5:392-6.

9 Sheffield VC, Carmi R, Kwitek-Black A, et al. Identification of a Bardet-Biedl syndrome locus on chromosome 3 and evaluation of an efficient approach to homozygosity mapping. Hum Mol Genet 1994;3:1331-5.

10 Carmi R, Rokhlina T, Kwitek-Black AE, et al. Use of a DNA pooling strategy to identify a human obesity syndrome locus on chromosome 15. Hum Mol Genet 1995;4:9-13.

11 Online Mendelian Inheritance in Man, OMIM (TM) Center for Medical Genetics JH, MD and National Cente for Biotechnology Information, National Library of Medicine (Bethesda MD). World Wide Web URL:http://www3 ncbi nlm nih gov/omim/ 1996.
12 Carmi R, Elbedour K, Stone EM, Sheffield VC. Phenotypic differences among patients with Bardet-Biedl syndrome linked to three different chromosome loci. Am $\mathcal{F}$ Med Genet 1995;59:199-203.

13 Croft JB, Morrell D, Chase CL, Swift M. Obesity in heterozygous carriers of the gene for the Bardet-Biedl syndrome. Am $\mathcal{F}$ Med Genet 1995;55:12-15.

14 Cookson WOCM, Sharp PA, Faux JA, Hopkin JM. Linkage between immunoglobulin $\mathrm{E}$ responses underlying asthma and rhinitis and chromosome 11q. Lancet 1989;i:1292-5.

15 Croft JB, Swift M. Obesity, hypertension, and renal disease in relatives of Bardet-Biedl syndrome sibs. Am $\mathcal{F}$ Med Genet 1990;36:37-42.

16 Collins F. Positional cloning: let's not call it reverse anymore. Nat Genet 1992;1:3-6.

17 Muragaki Y, Mundlos S, Upton J, Olsen B. Altered growth and branching patterns in synpolydactyly caused by mutations in HOXD13. Science 1996;272:548-51.

18 Banfi S, Borsani G, Rossi E, et al. Identification and mapping of human cDNAs homologous to Drosophila mutant genes through EST database searching. Nat Genet mutant genes thro 